\title{
INTERROGATING THE PRACTICE OF IMAGE MAKING IN A BUDDING CONTEXT
}

\author{
Ashraf M. Salama \\ Professor of Architecture, \\ Department of Architecture, \\ University of Strathclyde, Glasgow, Scotland, UK \\ ashraf.salama@strath.ac.uk
}

\begin{abstract}
Image making is a continuous worldwide practice of architects and designers whose concern is to create meaningful environments. Such a practice results in expressions that either reflect the regional context or mirror the wider global culture. This paper aims at interrogating image making practices in the city of Doha, which has experienced rapid urban transformations, associated with building large scale work and learning environments, mixed use developments, and cultural and sport facilities. Contextualizing current debate on Doha's architecture and urbanism, a critical analysis of geo-cultural politics and on the notion of the 'scapes of flows' is undertaken. Based on contextual, critical, and perceptual approaches image-making practices in the city were discerned. Different types of efforts were categorized and critically analyzed underlying the contextual and critical approaches. The analysis reveals that efforts range from utilizing symbolism in contemporary imaging, to manifesting tradition-modernity in search for image identity, to addressing the global condition towards image making. The perceptual approach established empirical evidence by investigating users' reactions to three notable office buildings that their design attempts to evoke a unique image. This was supported by statements made by CEOs of architectural firms and development companies that reflected a promise towards image making in the architecture of Doha. $A$ concluding critique is introduced to elucidate that while there are incessant attempts at image making, the practice of 'cutting and pasting' dominates in the absence of critical consciousness. Such a critique calls for avoiding 'case by case decision making' the urban governance in the city still adopts while engaging effective place making strategies.
\end{abstract}

Keywords: Image making; Symbolism; Globalization; Scapes of flows; Architectural identity; Doha

\section{INTRODUCTION}

Within the professional and academic communities the interest in creating meaningful places ${ }^{1}$ always result in a wide spectrum of approaches to place and image making. Architects and urban designers with interest in creating those places typically exploit different elements to emphasize a locality or reflect an international trend. These elements are represented through environmental imagery and formal aesthetics, and by depicting history, craft and cultural traditions, or current global trends. The sustained discourse on image making and symbolism in architecture is generally derived from the need to search for an identity. Regions, countries, and cities that have cultural richness and multi-layers of history seem to be obsessed with that search. Architecture of capital and major cities in the Gulf region are no exception where architects find themselves dealing with the irony of needing to project a certain image of whom

\footnotetext{
1 'Meaningful Places' as a term is used in both urban and environmental psychology literature. It is commonly introduced to refer to the way in which the physical aspects of the environment support spatial practices while at the same time associating images of those environments to the people involved (Altman and Low, 1992; Carmona et al, 2003; Hull, 1994).
} 
they are designing for while advocating the necessity of addressing the contemporary global culture.

While scholars in architecture may disparage the concern and curiosity to place emphasis on discussing building expressions and environmental imageries, the premise adopted by this paper is that since architecture is created for the public then examining its public face is essential to the interpretation of the juxtaposition of those expressions and images and the meanings they communicate and signify. In this respect, focusing on expressions and representations as reflected in the built environment does not mean reducing architecture to an appearance but recognizes that its public face is assimilated, comprehended and experienced by the public on a daily and routine basis.

Concomitantly, the objective of this paper is to endeavor to provide an insight into image making practices with a particular focus on the city of Doha, which has undergone significant transformation over the past two decades. ${ }^{2}$ In order to achieve this, a multi-layered critical discussion is employed to involve six components. The first is an attempt at contextualizing Doha within the regional cultural politics, with aim of demonstrating the impact of potential and actual regional forces on the image making interests and practices. The second is a mapping of the global condition on the profile of the city as reflected in the production of images and places. These two components offer a contextual background that places the subsequent investigation into focus.

The third component is identifying and conceptualizing theoretical underpinnings for understanding image making in terms of contextual, critical, and perceptual approaches; the fourth is reviewing design practices to identify the types of efforts that took place and that are currently taking place towards image making in the city; the fifth is mapping the contextual and critical approaches on actual examples from the city while employing key concepts to place such a mapping into focus, and finally utilizing the perceptual approach in a preliminary empirical study that examines users' reactions to image qualities of the environments they use. The relevance of the analysis presented lies in the fact that, while placing emphasis on the city of Doha, it contributes to the overall discourse in the Gulf region. Palpably, a number of capital and major cities, such Abu Dhabi, Dubai, and Manama, are undergoing transformations and witnessing image-making practices similar to those of Doha.

\section{CONTEXTUAL GEO-CULTURAL POLITICS OF AN EVOLOVING CAPITAL}

Historically, Doha - the capital of Qatar, was once a small fishing village whose main source of income was from pearl diving and the trade in natural saltwater pearls. Today, the capital is home to more than 90 per cent of the country's 2.0 million people; over 80 per cent of its current population consists of a majority group of migrant laborers and blue-collar workers, and minority groups of white-collar workers and professional expatriates from a wide variety of countries. Up to the mid-1960s, most of the buildings were clustered individual traditional houses that presented functional and efficient local responses to the surrounding physical and socio-cultural conditions. During the 1970s, with increasing oil revenues, Doha was rapidly transformed into a modernized city. Later, however, throughout the 1980s and early 1990s, the development process was much slower compared to the preceding period; this was due to the socio-economic impact of the first Gulf war in Kuwait and the heavy reliance of the country on the resources and economies of neighboring countries (Salama and Wiedmann, 2013). More recently, over the past two decades,

\footnotetext{
${ }^{2}$ While the city is growing rapidly urban governance adopted by local authorities still relies on a 'case by case decision making' which is manifested in the treatment of the urban environment in terms of individual buildings or gated and enclave developments leading to urban fragmentation rather than adopting place making strategies.
} 
the city has acquired a new significant geo-strategic importance (Taylor, 2003). ${ }^{3}$ Through the shift of global economic forces, Doha is now being developed as a central service hub between the old economies of Western Europe and the rising economies of Asia (Thierstein and Schein, 2008).

In the context of international competition between cities diverse new challenges are emerging as cities try to find ways to sustain their populace, expand their economy and extend their influence. With these aims in mind, architecture and the overall urban environment are tools being utilized by governments and decision-makers to help cities move forward in the intense global competition to establish themselves as key geographical and economic locations and destinations. Like its neighboring high-growth capitals, Doha has clearly defined ambitions and aspirations in this competitive global economy and in its attempt to distinguish itself on the world map; its new architecture is a dynamic tool to continuously manifest such aspirations (Salama and Wiedmann, 2013).

While Qatar is a small Arab and Muslim country, as part of the GCC-Gulf Cooperative Council it also has strong cultural and religious ties with a number of Levantine and Mediterranean countries. The threads of Mediterranean cultural and economic unity have been woven and intertwined through centuries of trade and cultural exchange and as such is actually a type of globalization, albeit on a much a smaller scale. These centuries-old cultural and economic connections have resulted in an amalgam of influences that can be clearly seen within models of cultural politics. Further, in the latter part of the last century, there was also the important influence of 'Pan-Arabism;' a secular Arab nationalist ideology designed to constitute one huge Arab-Islamic nation comprised of different societies, ${ }^{4}$ from the Atlantic Ocean to the Arabian Sea, linked together by common linguistic, cultural, religious, ties and a shared historical heritage. More recently, there has also been the less direct influence of 'Islamism,' a revivalist ideology that has largely displaced 'Pan-Arabism.' Across the Arabian Gulf, the influence of 'Islamism' may also be coming from the rigid ideologies of contemporary Iran or the conservatism flowing from Saudi Arabia, the heartland of the Arabian Peninsula. Although the Mediterranean and a consciousness of it existed long before the $20^{\text {th }}$ century, in the world of cultural politics, however, it would appear that traditional 'Mediterraneanism' has taken a back seat in recent debates while other competing forces, such as the Arab League, the European Union and the so-called 'Middle Easternism' have emerged as being much more influential.

In the context of contemporary debate on Mediterranean influences, two contrasting attitudes can be identified: the first perceives 'Mediterraneanism' as a bridge in terms of history and culture, while the second sees it as a dividing line or barrier or even both. The first attitude refutes Huntington's thesis of the "Clash of Civilizations" (Huntington, 1998), while the second reflects the typical North-South conflict, as expressed in a growing fortress mentality that has only one interest, merely political, which is the closing of the frontiers against the 'invasive' culture of the south (Mazzoleni, 2005). In this respect, Middle-East analysts and scholars voice the opinion

\footnotetext{
${ }^{3}$ The 'World City Network' ranks Doha as a Qatari city with the highest global connectivity (Taylor, 2013). Doha's man-made deepwater port serves as a regional container and trans-shipment point, which handles cargo across the Gulf. Doha has an inner-city international airport with one runway, which is currently running out of capacity given the recent rapid growth of the city. A new airport further outside the city with two runways, parts of which were finalized in 2012 and a new international seaport, planned for completion by 2015 , are currently in their completion phases.

${ }^{4}$ Pan-Arabism, a secular Arab nationalist ideology, was founded in the late 1920s by the Syrian modernizer, Michel Aflaq. PanArabism was later championed aggressively by the former Egyptian president, Gamal Abdul Nasser who called for the rejuvenation of and political union within the Arabo-Islamic world. The core ideology of Pan-Arab nationalism was the premise that the societies of the Arab World, from the Atlantic to the Gulf, constitute one nation bound together by common socio-cultural and economic interests. In an attempt to encourage and initiate a development program of modernization and secularization, Nasser exploited and capitalized on the anti-imperialist public feeling of the 1950s to become the leader and promulgator of an inclusive pan-Arab ideology. This scheme, however, met staunch opposition from Muslim traditionalists. Hence, by the late 1960s, 'Pan-Arabism' declined and eventually disappeared as an ideology after what is called 'Arab defeat' in 1967 (Salama and Wiedmann, 2013).
} 
that an attempt to rebuild and reinforce the Euro-Arab partnership is critically needed. 'Middle Easternism,' on the other hand, was introduced to the world community in the 1950s, with the intention that the region become more culturally inclusive while making at the same time, but to a lesser degree, a concerted effort to respond to and accommodate the influences of other nonArab countries.

Both 'Mediterraneanism' and 'Middle Easternism' have been described as 'partnership' and 'conflicting' models; even so however, they have several features in common. Both models involve polar partners and, in the context of current globalization, it is essential that none of the partners ignore the others; this discourse is primarily characterized by a so-called downfall or breaking-down of barriers between regions and societies. Nonetheless, some voices from poorer Arab nations are now arguing that the globalization paradigm is paused as local problems exemplified by economic hardship, poverty, and political instability are a much stronger influence than the idea of a global world and as such its potential has not been realized. In contrast, other voices from oil and gas-based economies recognize, interact and positively welcome the impact of globalization.

Cultural politics in recent years have had a tremendous impact on development, architecture, and urbanism as the result of mutual partnerships, transnational practices and the inflow and outflow of capital and people. Although 'Mediterraneanism,' 'Middle Easternism,' 'PanArabism,' 'Islamism,' and 'nationalist particularism' are constructs that serve widely differing political ends, they are of important heuristic value: they bring into focus questions about identity and the sharing of deeper meanings at the cultural and human existence levels (Salama, 2005). The unique cultural and advantageous geopolitical position of Qatar and its capital Doha, has created a rich professional environment for architectural experimentation where many interventions have emerged, thus originating representations in search for meaning (Sadria, 2012; Salama, 2011).

\section{DOHA AND THE GLOBAL CONDITION}

Urban theorists, historians, and geographers have been conjecturing globalization as a phenomenon and the consequential global flows since the early 1990s. The conception of the 'space of flows' was introduced by Manuel Castells. He argues that contemporary societies are structured around flows of capital, information, technology, images, sounds, and symbols (Castells, 1996)..$^{5}$ The revolution in communication technologies and transportation, which was prompted by the commercialization of the Internet, has contributed to the acceleration of experiencing time and the deceleration of the importance of distance. This is a characteristic of the global era and is referred to as 'time-space compression' (Harvey, 1990). It has expedited the integration of social, cultural, economic, and political processes and systems across the world, which has resulted in what is called 'global flows.' These flows represent movements of people, capital, information, and knowledge; have emerged in the last two decades (Salama, H. 2013). Nonetheless currently they are occurring at unprecedented rates and are contributing to an increased connectivity between places, cultural integration and economic interdependence while triggering new images and the restructuring of urban forms and cities. ${ }^{6}$

\footnotetext{
${ }^{5}$ While the notion of flows can be validated, Castells' assumption that the global city is not necessarily a place but a process has not proven true. This is clearly evident in the rise of globalizing cities such as Abu-Dhabi, Doha, and Dubai that are witnessing continuous urban development and rapid growth processes as a result of these flows.

${ }^{6}$ In earlier writings by the author, the notion of the 'scapes of flows' within the overall context of the Arabian Peninsula was elaborated. See Salama, Ashraf M. "Identity Flows: The Arabian Peninsula, Emerging Metropolises." In Atlas Architectures of the 21st Century Africa and Middle East, edited by Luis Fernández-Galiano, 175-221. Madrid: Spain, 2011. Other scholars, however, have addressed these flows in specific contexts. Hussam H. Salama discussed such a notion in the context of the Emirate of Dubai while Yasser Mahgoub discussed it in the context of the city of Kuwait. See Salama, H. H. "Dubai in a World of Flows." Archnet-IJAR: International Journal of Architectural Research 7, 2 (2013): 136-145.
} 
In essence, dramatic changes in the ways people communicate and interact have drastically impacted trends of urban development. While these changes posture severe confrontations with local cultures and identities, they offer opportunities to developing cities through access to global capital and knowledge. The emergence of new urban landscapes was instigated by the powerful exposure to 'global flows.' Arjun Appadurai names global cities 'scapes of flows,' and identifies five types of flows: Ethnoscapes, Mediascapes, Financscapes, Technoscapes, and Ideascapes (Appadurai, 1900, 1996).

Mapping these 'scapes of flows' on the current profile of Doha key features of globalization and 'global flows' become evident (Figure 1). The first 'scape of flows' is Ethnoscapes, which are created by the need for workforce and the interaction of various cultures where may expatriate professionals live, work, and visit those cities. Travelers and tourists, migrants and immigrants, refugees and exiles, are moving from one place to another, contribute to the shaping of urban landscapes. This is manifested both in the population profile of Doha and in the rising numbers of travellers and temporary visitors. Mediascapes, is the second 'scape of flows,' are generated by the expanding role of media and can be seen as a concomitant result of the revolution of information technology. Media cities, Internet, and TV news channels such as alJazeera are major sources of information and knowledge and a clear manifestation of the role of media (Figure 2).

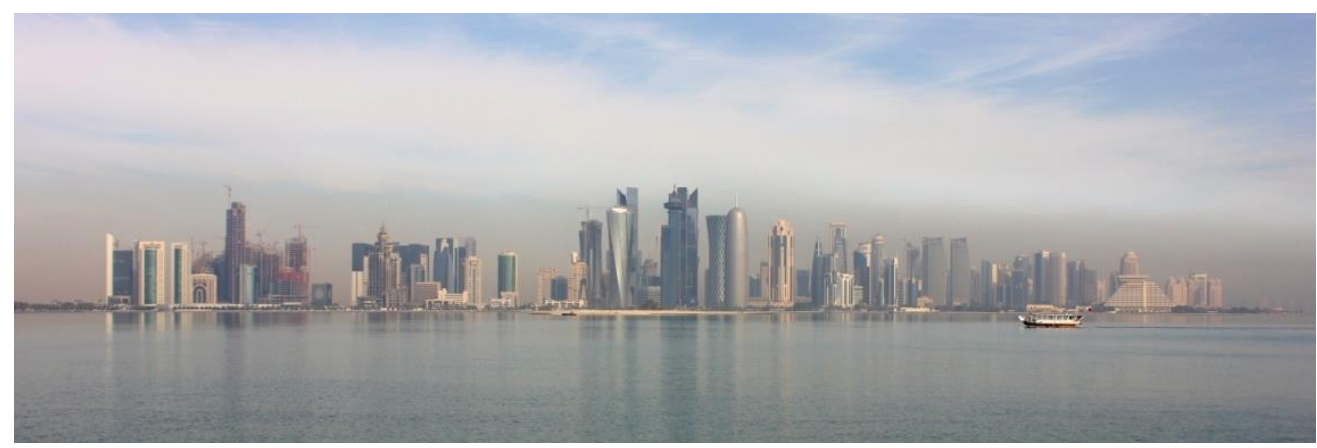

Figure 1: Doha skyline and the new business district, a manifestation of the global condition (Source: Author).

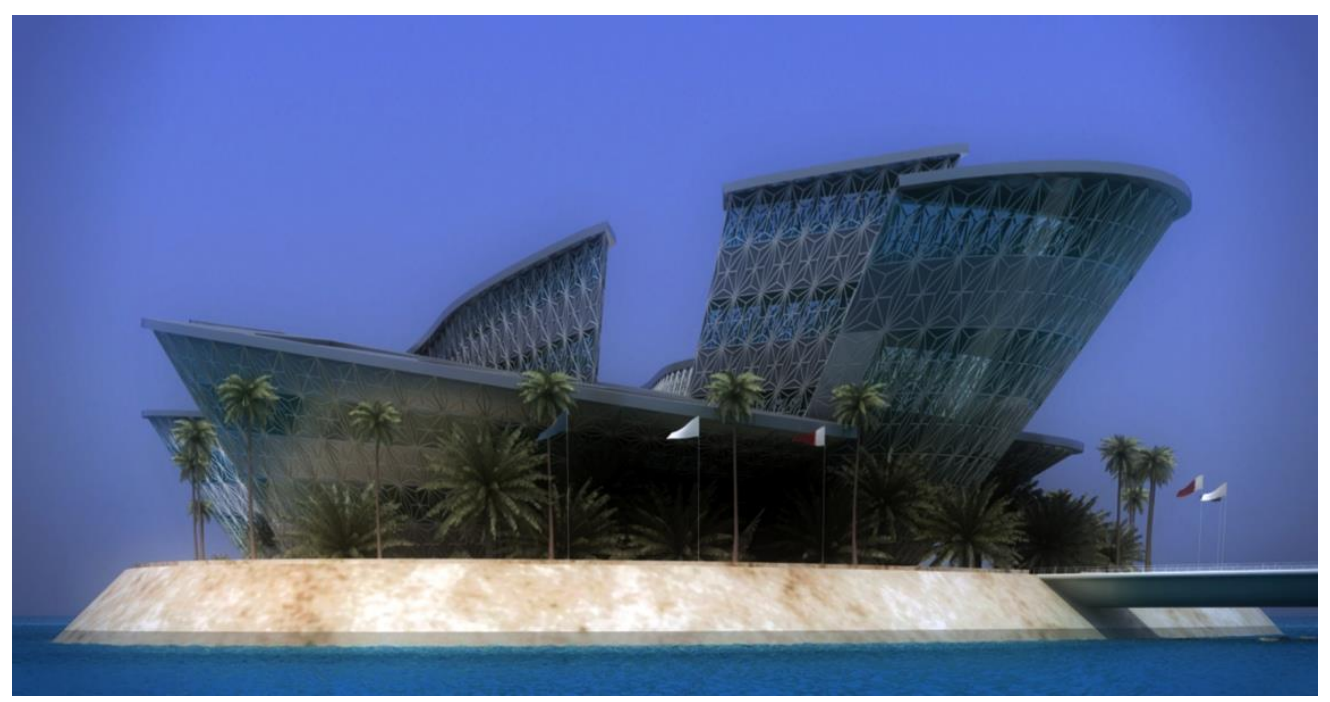

Figure 2: An alternative concept design for a new Al Jazeera News Headquarters, by Digital Artist Mohannad Khamra, a reflection of the mediascapes (Source: www.behance.net). 
The third 'scape of flows' is Financscapes, which are landscapes, created by the flow of capital and the establishment of transnational financial corporations, stock exchanges, and currency markets (Figure 3). Technoscapes is another type of 'scape of flows,' which reflects the impact of telecommunication technologies on contemporary urban life. Emerging high-tech industries and the establishment of FTZs-Free Trade Zones and science and technology parks in Doha are an evidence of the impact of technoscapes (Figure 4). The fifth 'scape of flows' is Ideascapes; landscapes that are resulting from the spread of cultural flows, ideologies and the counter ideologies. The Education City in Doha including its the international branch campuses and the surge in the construction of museums is a clear example of the impact of ideascapes (Figure 5).

By and large, these 'scapes' are important players in the shaping of social and professional practices and the resulting spatial environments that accommodate them. They accentuate the role 'global flows' play in shaping contemporary development processes and the resulting images. Architecture and urbanism in Doha continues to be viewed as a crucial catalyst for cities to sustain their position in the milieu of a 'global flows.'

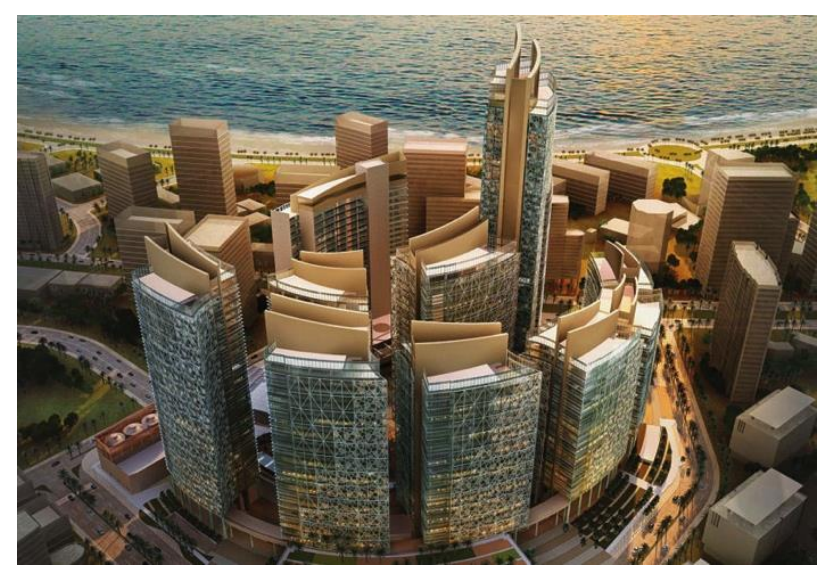

Figure 3: Barwa Financial District (renamed Qatar Petroleum Financial District) by KEO International, a manifestation of the financscapes (Source: Courtesy of KEO).

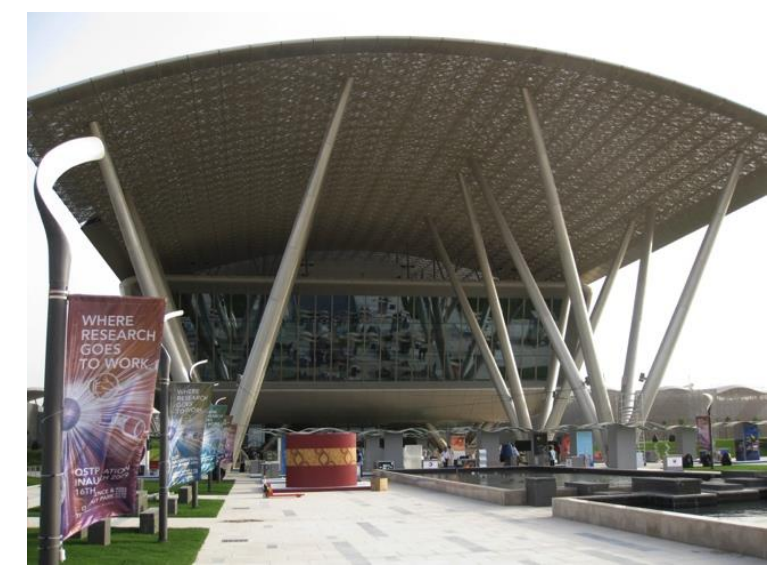

Figure 4: Qatar Science and Technology ParkQSTP, by Woods Bagot Gobal Studio, an example of the results of technoscapes (Source: Author).

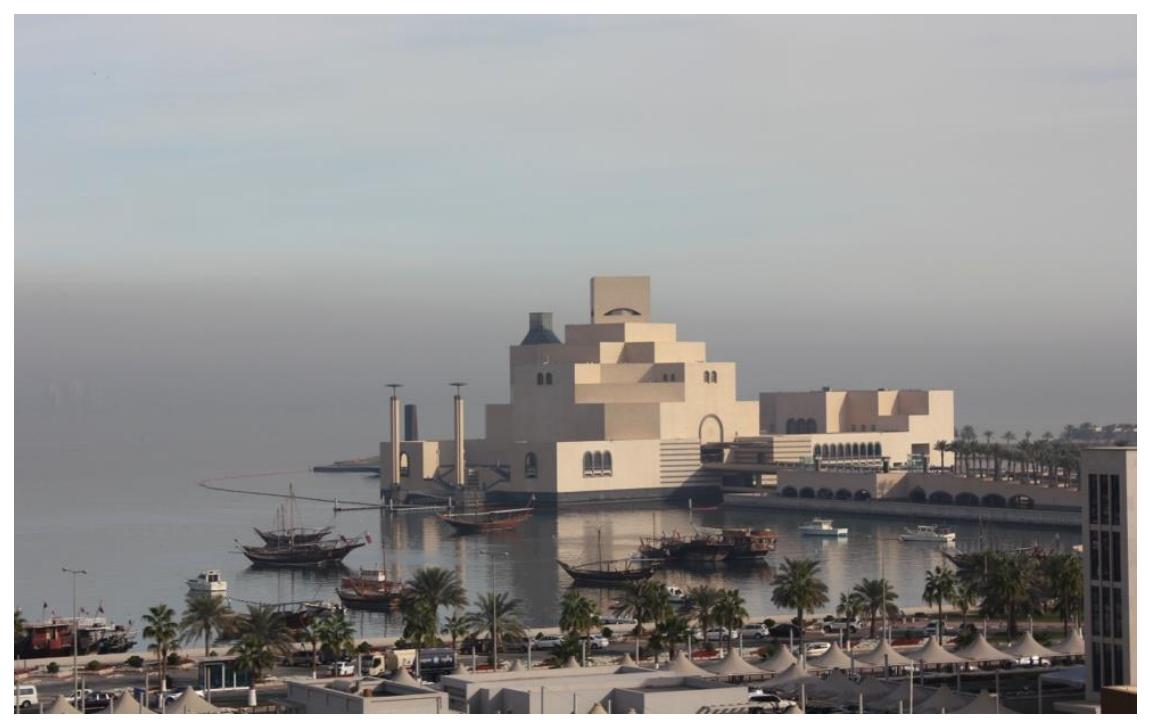

Figure 5: Museum of Islamic Art, by I.M.Pei, an example of the results of cultural flows and ideascapes (Source: Author). 


\section{THEORETICAL UNDERPINNINGS ON IMAGE MAKING}

While most architectural and urban design practices are oriented to functional, pragmatic, environmental, and economic concerns, a number of theorists and practitioners are in a continuous quest for a deeper design discourse that employs discussion of local expressions and contextually-based imagery toward creating place identities (Larice and Macdonald, 2007). The globalized city condition resulting from the 'scapes of flows' has created a sense of placelessness. ${ }^{7}$ As a reaction, evoking a sense of place through image making has become a primary concern in contemporary architectural and urban design practices. With this concern, the aspirations are to show history, to introduce new work and living environments, or to articulate how comfort, entertainment, and emerging interventions that accommodate new lifestyles are enjoyed by the public, or a combination of these. These aspirations are supported and sponsored by government agencies and key economic players in shaping the built environment such as real estate developers and city marketers. The pursuit for realizing these aspirations has - in many cases-culminated into a type of symbolism that is painful to comprehend (Salama, 2005). Larice and Macdonald (2007) argue, and rightly so, that "the results have been mixed, resulting both in places that authentically incorporate a sense of place, as well as places that utilize inauthentic and shallow forms of 'theming' to evoke past histories and otherness" (Larice and Macdonald, 2007:151).

The notion of image making and its contribution to the city image has been a subject of discussion by theorists and academics since Lynch's Image of the City (1960). Contemporary literature, however, has expanded beyond the work of Lynch to include other parameters for understanding image making. Conceptually, three approaches can be identified to understand the scope of relevant interests and studies in the field of environmental imagery. These are contextual, critical, and perceptual. In this respect, image making is dealt with as integral aspect of place making and as a result of the various forces that contribute to the shaping of places.

The contextual approach fosters an understanding of place by focusing on the regional, historical, and natural aspects of the city or the region within which it exists. The principal theories and practices of this approach have emerged as a reaction to the dissatisfaction with the universal nature of modernism. Critical regionalism, coined by Frampton and elaborated upon by Tzonis and Lefaivre, is the primary theory of this approach (Frampton, 1985; Tzonis and Lefaivre, 2003). It adopts the principle that the reading of a region's history to extract its essence and utilize it to suit the spirit of the time should be a primary design focus. The theory recognizes the interactional value of climate, culture, religion, and craft in making an image. The manifestations of critical regionalism are typically viewed as a way to show cultural, economic, and political independence. In essence, the approach has resulted in a growing interest in discussing the role of identity creation through visual qualities of buildings and the landscape. Directly and indirectly, architectural discourse in the Middle East and the Gulf region has profoundly related contemporary practices to the discourse on regionalism (Ozkan, 1989; Eben Saleh, 1998; Salama, 2005; Asfour, 2007; Mahgoub, 2007).

The critical approach involves descriptions that analytically discuss the practice of contemporary image making and the growing culture of fictionalizing and capitalist profit-seeking practice. The writings of Harvey (1989) and Huxtable (1981) and other critics have emphasized the value of authentic representation ${ }^{8}$ for contemporary societies. Yet, one underlying notion of

\footnotetext{
${ }^{7}$ Richard Sennett $(1970,1992)$ discussed the notion of dissolution of space and in particular the public space of the contemporary city.

${ }^{8}$ The belief that a building represents something by referring to something, which is not present, oversimplifies the fact that buildings should be experienced. This is to say that what the building represents is part of our comprehension and understanding of the building. According to Dailbor Vesely (2004) such an experience and understanding of the building or the environment refers to what is called authentic representation or character.
} 
this approach is the introduction of iconicity. Several theorists in various fields including sociology and architecture introduced the notion of 'iconic' either to refer to identity and symbolic representation (Strauss, 1969; 1991), or to refer to the use of 'icons' as part of the design process (Broadbent, 1977). Nevertheless, Jencks (2005) introduced 'iconic' at the urban scale, as a term to denote buildings that involve the incorporation of important and enduring symbols that stand out of the city. He argues that they must be powerful in the sense that they symbolize a memory or nostalgia of an unusual importance. Practices toward materializing iconicity can be witnessed in contemporary developments worldwide and in the growing interest in developing iconic buildings and urban settings throughout Middle Eastern cities.

The perceptual approach places emphasis on the relationship between the physical qualities of the urban environment and those who perceive and comprehend such qualities. ${ }^{9}$ The approach concerns itself with aspects that are likely to influence memory, orientation, and the public image of the environment. Advocates of this approach emphasize the importance of visual imagery in making cities legible, comprehendible, and memorable (Lynch, 1960). Others, emphasize the relationship between the physical qualities of architecture and urban space and memory, sensory experience, and emotional responses (Cullen's, 1961, Pallasmaa, 2005). These two areas of interest were heavily adopted by the environment-behaviour research (EBR) community (Sanoff, 1974, 1991; Zube 1984; Nasar, 1988; Stamp, 2000). However, they have received little or no attention among both scholars and practitioners in the Gulf region.

\section{EXAMINING IMAGE MAKING IN THE CITY OF DOHA}

In order to explore aspects relevant to image making processes within the city of Doha, the contextual, critical, and perceptual approaches were employed to form a combined methodology for investigation (Figure 6). As such, based on reviewing design practices three types of efforts towards image making were identified. These are: a) utilizing symbolism in contemporary imaging, b) manifesting tradition and modernity discourse in search for image identity, and c) addressing the global condition towards image making. The contextual and critical approaches were utilized to develop a critical analysis while employing key concepts that are mapped on actual examples from the city. In this respect, the analysis is directed towards place character and regional history, which act as sources for image and identity creation.

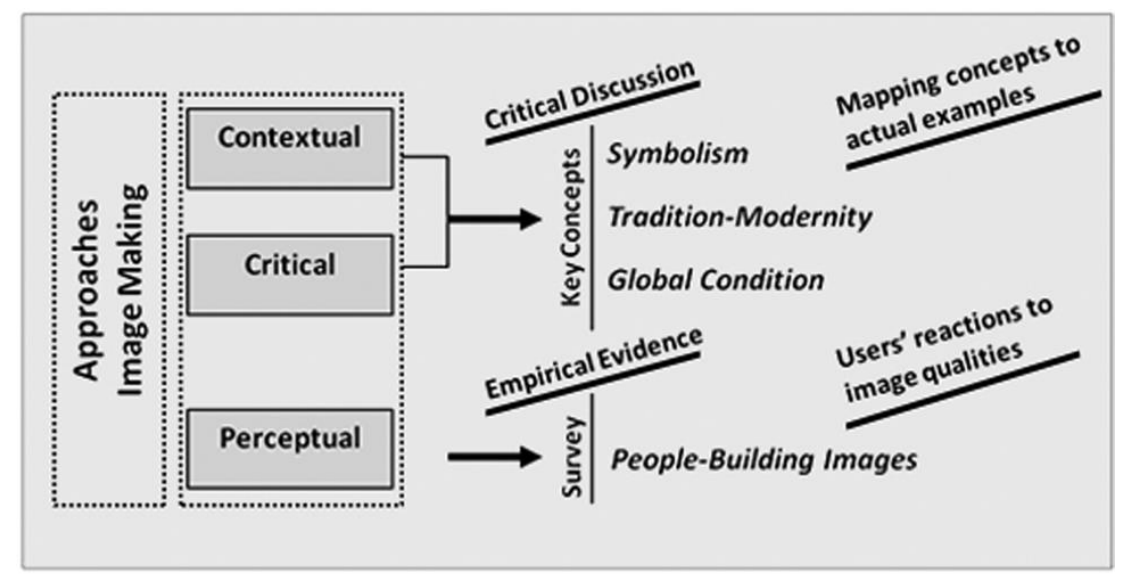

Figure 6: An integrated approach for investigating image-making practices in the city of Doha (Source: Author).

\footnotetext{
${ }^{9}$ It is noted that the perceptual approach in the context of this paper is introduced as a form of Post Occupancy Evaluation-POE. Nonetheless, it focuses on reactions of building users to environmental images rather than assessing spatial dimensions as they relate to building users.
} 
The perceptual approach is adopted through a preliminary empirical study of three notable office buildings that their design involves an image making effort. Buildings were identified based on their distinctive visual qualities, which attempt at blending traditional imagery ${ }^{10}$ into a contemporary office environment. Users of the three buildings were surveyed by asking them to react to whether the building does satisfy a number of qualities, namely: advanced outlook, modern technology, traditional local image and detailing, identity (uniqueness and distinction), and Islamic and cultural values. A total of 382 responses, with over hundred responses from users of each building, were received. The results reflect users' reactions to the environment in which they work and the differences in their perception of the five qualities presented to them.

\section{CONTEXTUAL AND CRITICAL APPROACHES TO IMAGE MAKING}

Contextual and critical approaches are utilized towards a deeper understanding of evolving image-making practices in the city of Doha. Critical analysis of the identified types of efforts toward image making is outlined in the following three sections.

\section{Utilizing Symbolism in Contemporary Imaging.}

It is argued that the acts of symbolization and cultural and personal attachment to what is called 'symbols' are recognized modes of thinking, feeling, behaving, associating, and understanding (Grabar, 1980). Two origins of symbolism can be introduced in the context of this discussion; social and spontaneous creation of new places or buildings by the public, and planning or intentional actions of those who have the power and authority to introduce change in the urban environment (Salama, 2005). If an organism or a component of a social structure is able to intentionally introduce change in the environment one can argue that it is a wielding power. This purposive action aims at endowing space with shape, structure, elements, and name with an attempt to highlight some values, aesthetics, or facts to stand in the minds of the public. It is intended to create a symbolic space ${ }^{11}$ or building with preconceived meaning that can or cannot be comprehended and assimilated by the public as a point of reference, and that might or might not become a shared symbolic element. This corroborates the fact that most of the important urban and building actions and artistic interventions in the city of Doha are intended to evoke a memory, an event, a person, or to put a political, artistic, or social moment on record (Figures 7-a $\& b)$.

In many development efforts in the Arabian peninsula and the city of Doha is no exception, developers and decision-makers of projects are actively promoting, together with professionals, an increased use of traditional symbols in order to enhance building images and the urban context within which they exist. The ultimate goal is to establish an architectural and spatial language that speaks to the public and the context.

By and large, the search for historical and discernible symbols can foster a sense of identity while promoting a desired type of intimacy between a community and its surrounding physical environment. It is argued that the use of symbols derived from architectural heritage invigorates the preservation of traditions and the tangible elements of cultural heritage. In fact, the desire to instigate a sense of belonging by replicating, through built form, the visual attributes, signs, and symbols of historical or traditional architecture keeps encouraging professionals to increase the use of historic symbols in their contemporary practices toward creating iconic

\footnotetext{
${ }^{10}$ The term traditional imagery is introduced to refer to the utilization of images derived from historical or vernacular precedents in contemporary buildings.

${ }^{11}$ In his writings on spatial quality Amos Rapoport discusses the notion of symbolic space and that a space can be symbolic. Arguing that in order to understand spatial symbolism we must recognize the underlying cultural imperatives of the people concerned (Rapoport, 1970).
} 
buildings or urban settings that establish links with the past. Examples of efforts toward materializing these desires are evident in a considerable number of buildings and projects within the city of Doha. (Figure 8-a \& b).

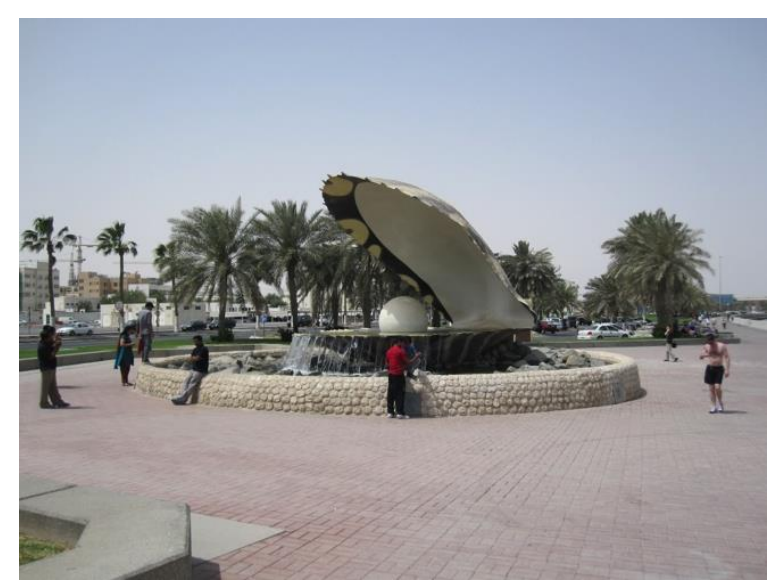

a: depicting the pearl in a public space in Doha's waterfront.

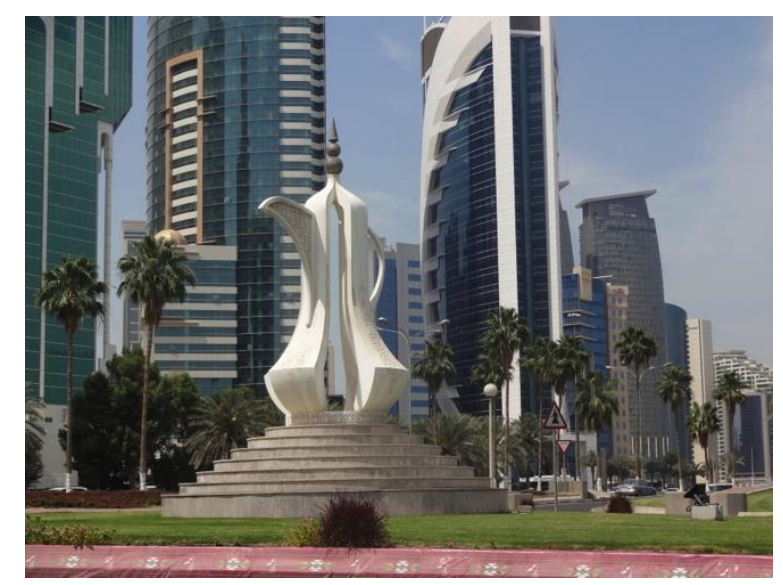

b: using the 'dallah;' traditional coffee pot-the Arab symbol of welcoming.

Figure 7: Utilizing symbolism in Doha's urban spaces (Source: Author).

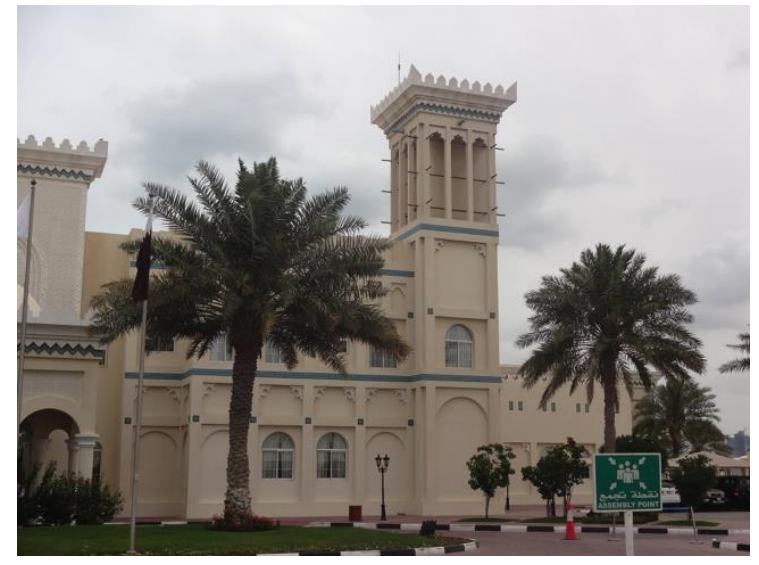

a: Doha Diplomatic Club.

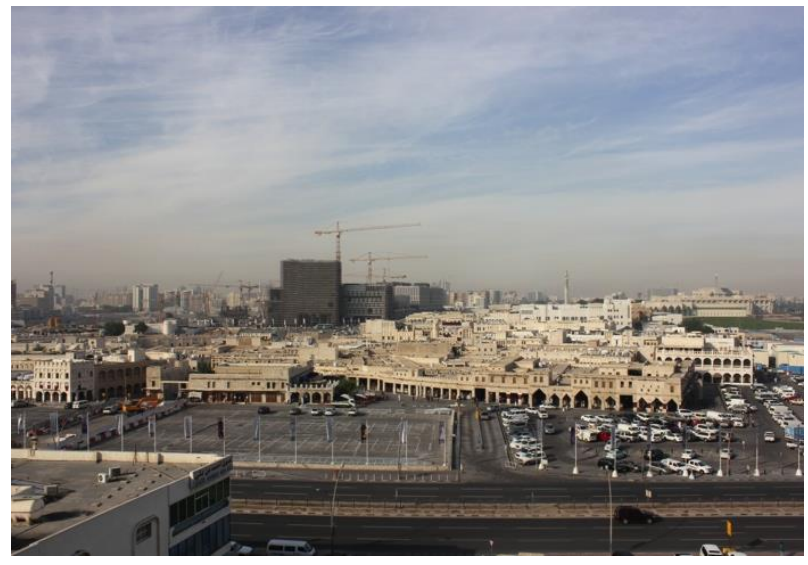

b: Souq Waqif reconstruction and conservation project.

Figure 8: The use of distinct regional elements to cultivate a sense of identity (Source: Author).

\section{Manifesting Tradition-Modernity Dialogue in Search for Image Identity.}

Addressing the sensitive relationship between tradition and modernity is another approach that manifests continuous attempts to construct architectural or urban identity towards the making of an image or iconic building. Tradition in this respect can be seen as an internal action or as a reaction to external forces. In essence, the result of the interaction between internal influences and external forces creates an identity.

The narrative of expressing cultural identity through architecture and urban form keeps presenting itself on the map of architectural practices and urban discourse. While some theorists see identity as a human need that has transformed itself into a necessity (Correa, 1983 and Saliya 1986), others regard it as a process of constructing meaning on the basis of giving priority to a set of cultural attributes over other sources of meaning (Castells, 2004). Along the same line of thinking, Hall argues, "cultural identity is a matter of 'becoming' as well as of 'being' and that it 
belongs to the future as much as to the past." (Hall 1990:225). Two polar qualities appear in Hall's position reflecting a more in depth understanding of identity. One relates to similarity and continuity, while the other recounts difference and rupture.

Consequently, identity appears to have three underlying qualities: a) the permanence over time of a subject unaffected by environmental changes below a certain threshold level, b) the notion of unity, which establishes the limits of a subject and enables us to distinguish it from the others, and c) a relationship between two elements, which enables us to recognize them as identical. This connotes that permanence, recognition, and distinction determine the presence of identity in a physical object, a work of architecture, or a portion of a built environment (Salama 2005). Identity can be understood as the collective aspect of the set of characteristics by which an object or a portion of the built environment is definitively recognizable. ${ }^{12}$

Doha's earlier attempts at image making can be seen in the buildings of Qatar University campus, where a visual dialogue was established between traditional design elements and the utilization of the contemporary technology (Figure 9). As the discourse continues on the dialectic relationships between tradition and modernity, the contemporary and the historic, and the global and the local, a number of important projects exemplify the presence of multiple resistant identities. Some architects have continuously attempted to address such a balance in their work (Figure 10-a \& b), by developing syntheses of contemporary images based on revived traditions and by simulating traditional environments, in some cases using modern technologies while in other cases combined with traditional techniques. These endeavors aim at returning architecture to its former position of being an expression of society, and arising from within it (Salama, 2008; Henrdrix, 2010).

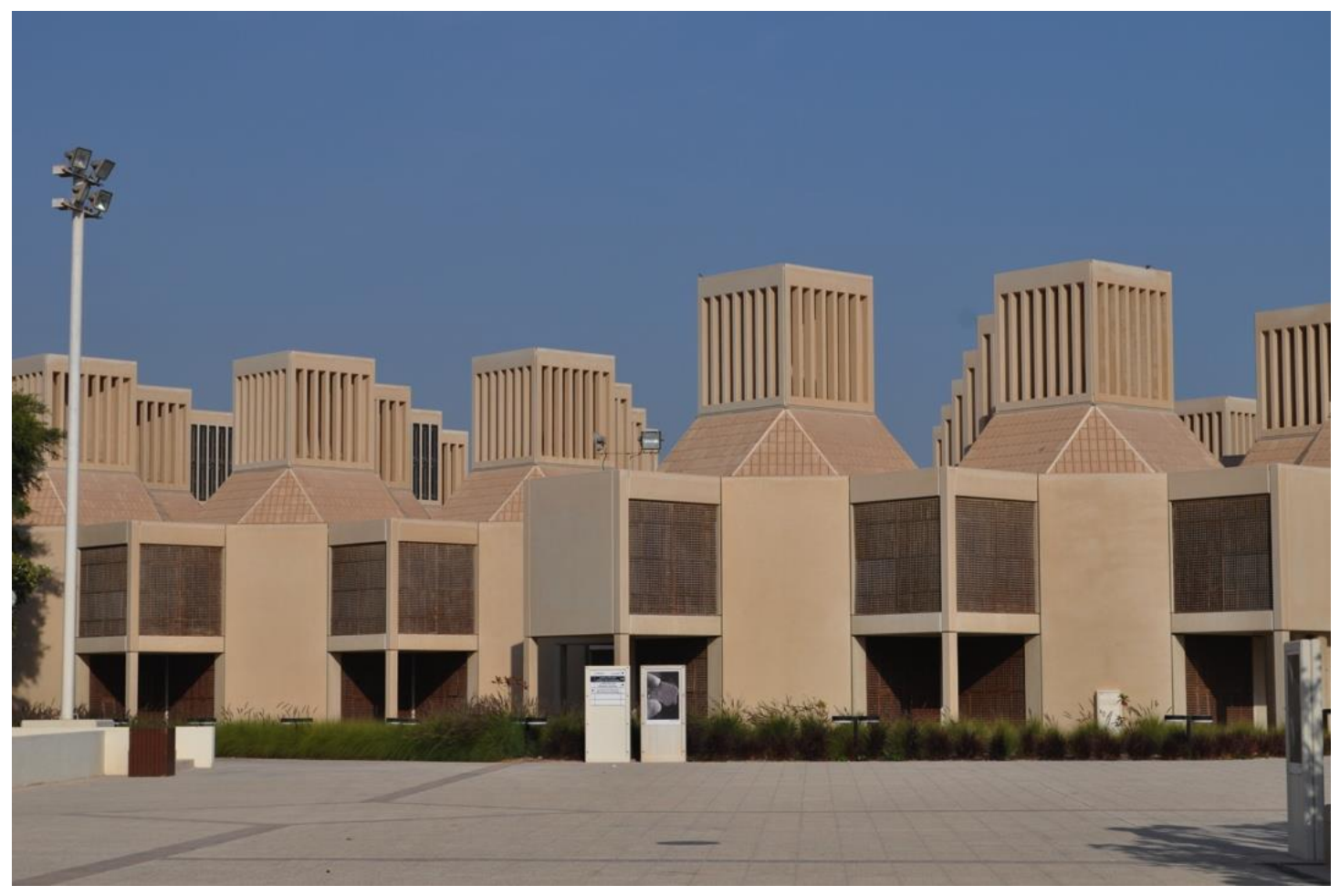

Figure 9: Qatar university campus by the late Kamal Al-Kafrawy

(Source: Author-Photography by Raghda Salama).

\footnotetext{
${ }^{12}$ While this comprehensive definition of identity reveals important factors-namely permanence, distinction, and recognition, they were not scrutinized as part of the study since their examination goes beyond the scope of the discussion.
} 


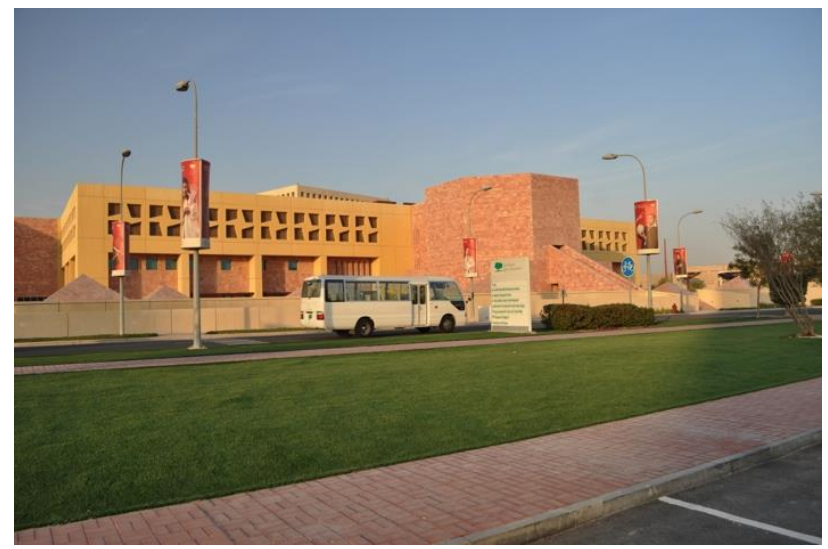

a: Engineering building of Texas A \& M University at the Education City by Ricardo Legoretta.

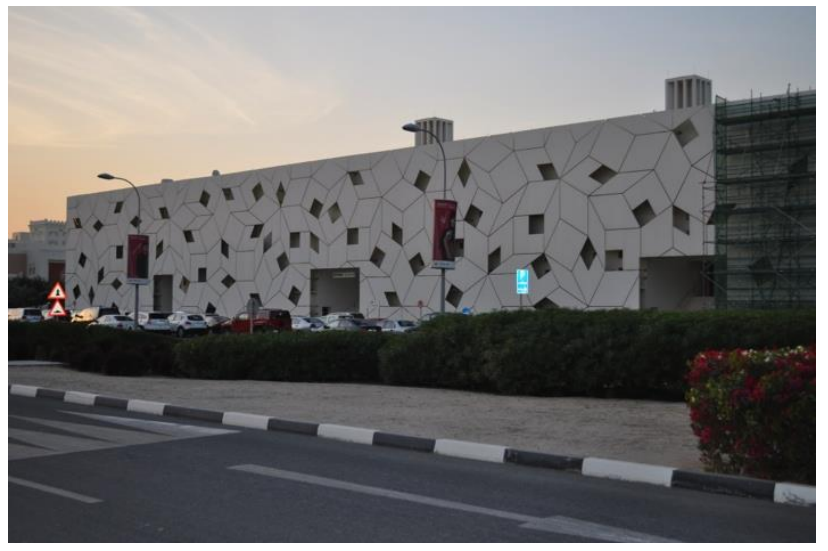

b: Liberal Arts and Science building at the Education City by Arata Isozaki.

Figure 10: Rooting contemporary architecture in the application and re-interpretation of regional traditions (Source: Author-Photography by Raghda Salama).

\section{Addressing the Global Condition Toward Image Making}

Through the shift of global economic forces, some cities have acquired geo-strategic importance and have developed to central hubs between old economies of Western Europe and the rising economies of Asia. In the context of international competition between cities new challenges are emerging. Architecture and urbanism continue to be regarded as a crucial catalyst for cities to sustain their position in the milieu of a global knowledge intensive economy. Reactions to this global condition can be seen in infinite and hybrid urban forms and typologies.

The global condition and its impact on the city and the production of space have been heavily discussed in the literature (Lefebvre 1991, Stillerman 2006). City branding or urban branding is one of the reactions to such a condition. As a rising area of discourse, it has emerged as a response to growing global and fiscal competition (Ole 2005, Synnott, 2010). It is witnessed in the realization of local and regional aspirations to entice global investment or gain international attention. In this context, two phenomena toward image making can be identified.

The first phenomenon can be seen in the organization of large scale stage and hall mark events such as the case of ASIA-D 2006, where the city of Doha has branded itself as a sport based city through organizing the Asian Games in 2006, which is considered the second largest sporting event in the world, after the Olympic Games itself (Hasanin, 2007). Through the use of environmental graphics, distribution of billboards throughout the city, installing sculptures in public spaces, using pictograms in buildings and street wraps, key areas within the city acquired a new image (Figures 11-a \& b). While such an image can be considered a temporary one, pursuing an event of this scale typically results in improving infrastructure, development of public spaces, and introducing new amenities. The successful result of such a branding strategy encouraged the government to host a series of regional and international events, and eventually led the city to prepare itself to host the World Cup in 2022, which will eventually have dramatic effects on the image making processes and practices.

The second phenomenon can be seen in the creation and promotion of urban districts or enclave developments for key segments of society. These types of projects stem from alliances between the government agencies and business interests. Through promoting new work and lifestyles, new urban images are generated in key areas within the city. Examples manifesting this phenomenon are evident in two major development projects. The first project is the water front West Bay development, considered to be the new Doha's business district, introduced and promoted a new image for the city through a high-density development consisting of high cost- 
high rise glass towers (Figure 12). The second project is the Pearl development, a man-made island conceived in an exclusive development of four million square meters and $32 \mathrm{Km}$ coastline. Different eclectic and hybrid styles of regional and European architecture are used for introducing a distinctive image in the development (Figure 13-a \&-b). While in the first type individual buildings compete in shaping the urban image, priority for image making in the second project is given to the overall urban setting and activities rather than to buildings individually.
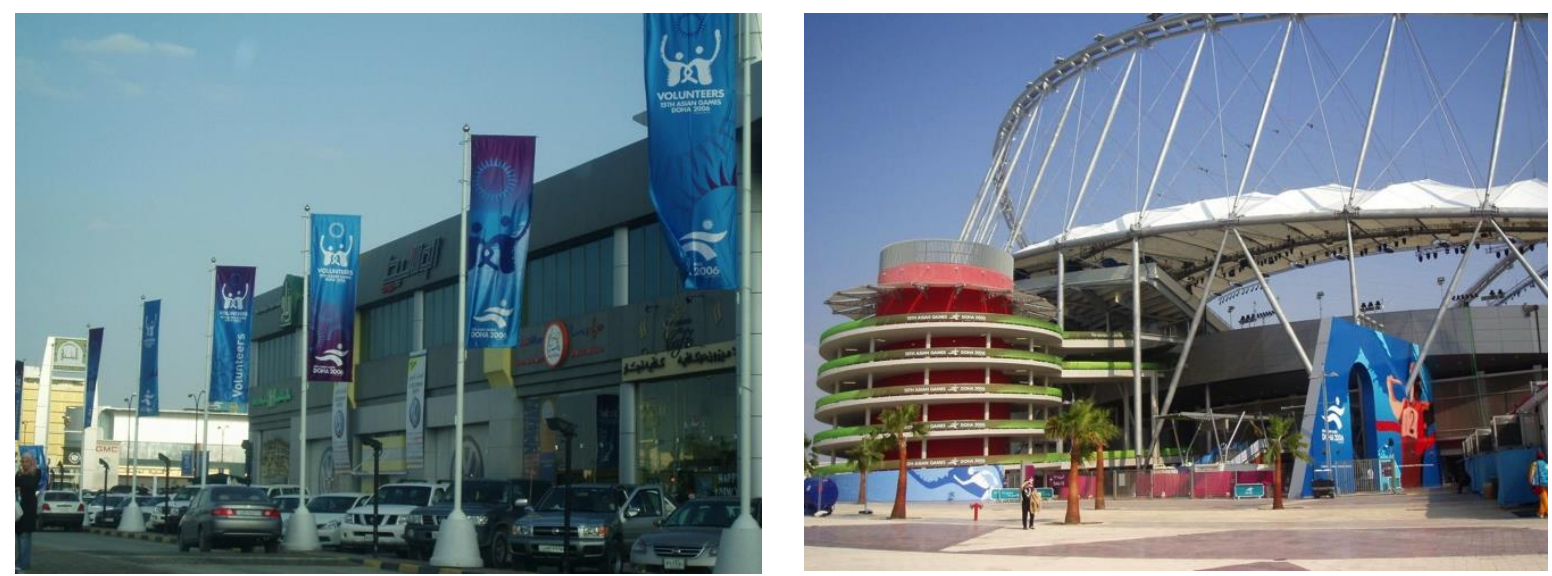

Figure 11-a,-b: Branding Doha-ASIAD: 2006 Asian Games, the use of environmental graphics, pictograms, and building wraps (Source: Author-Photography by Abeer Hasanin, 2007).

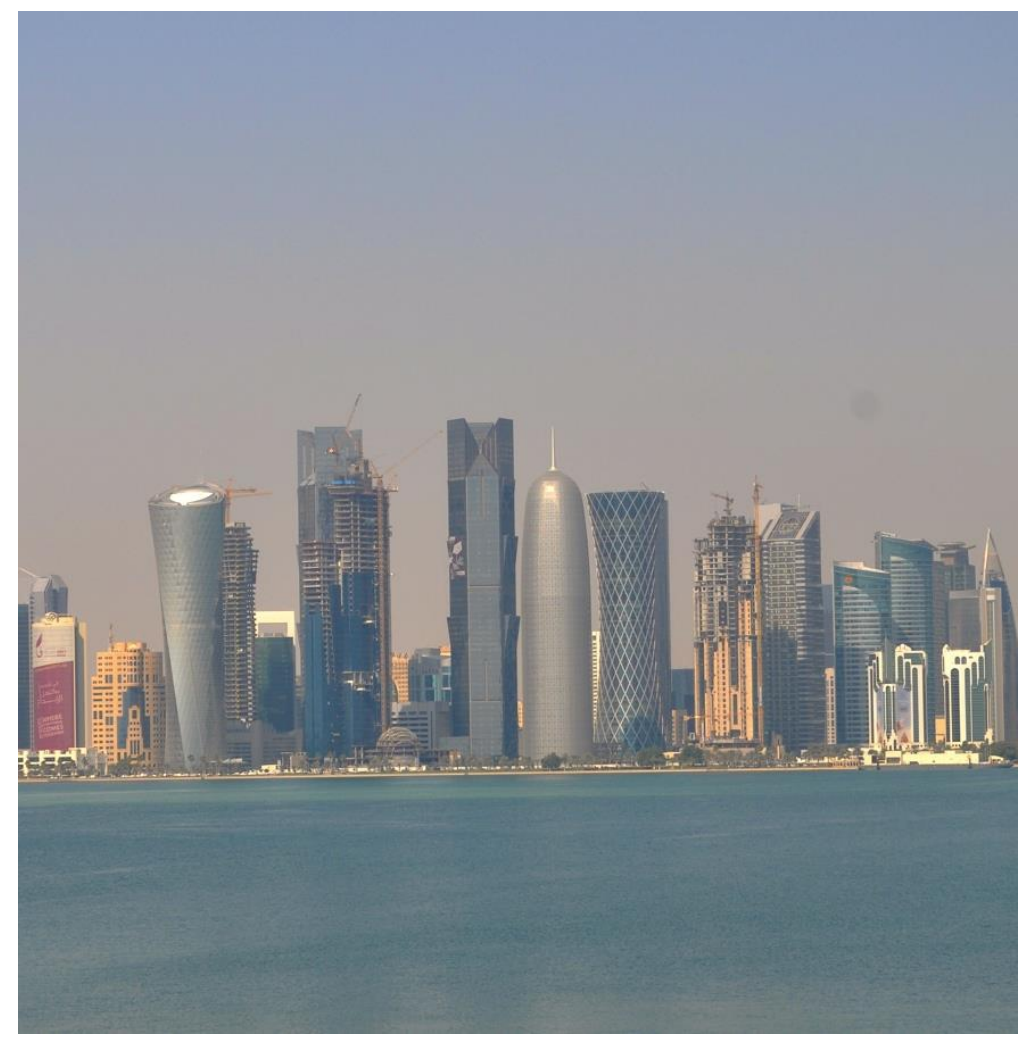

Figure 12: Individual buildings compete to create an iconic urban image to meet the globalized city interest: Doha's water frontWest bay Development (Source: Author). 

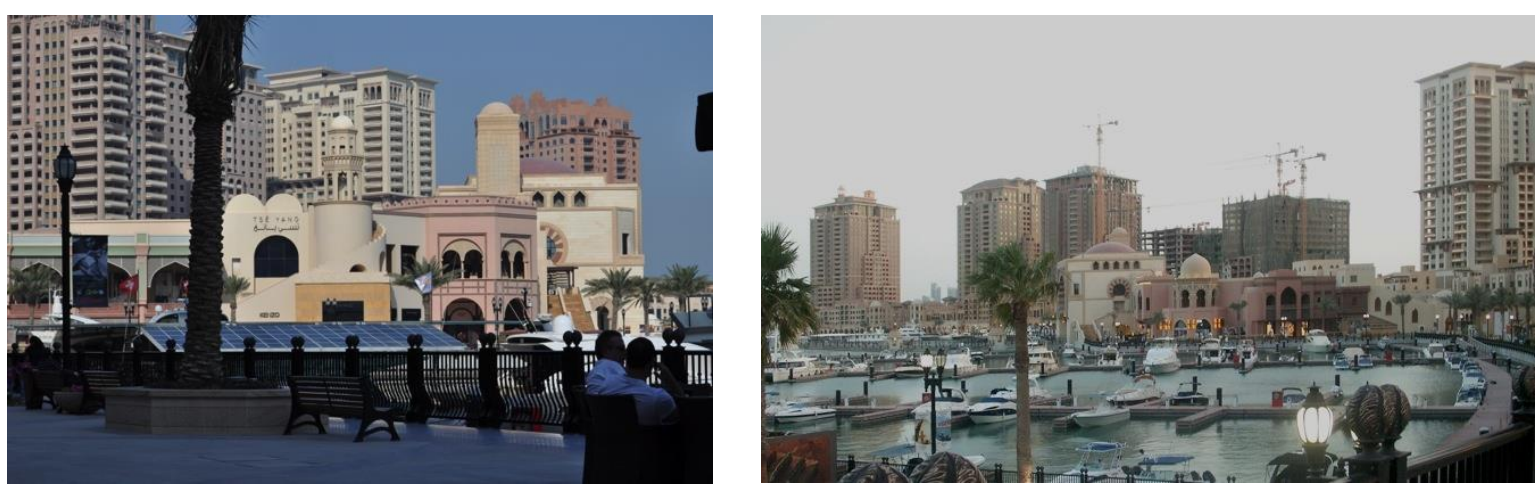

Figure 13-a \&-b: Dominance of the setting over individual buildings; eclectic and hybrid regional and Mediterranean styles in the Pearl development (Source: Author).

The previous analysis indicates that the three identified types of efforts towards image making contribute to the understanding of the overall environmental imagery of the city. It is noted, however, that the first two types are based on establishing visual references borrowed from the past. They delineate attempts to construct architectural and urban identity through the selection of historic features stemming from the Arabic heritage. The third type, however, results in 'multiple modernities,' which refers to socio-economic transformations characterized by a desire to position Doha as an aspiring global city. The presence of different trends towards image making signifies that there are forces of modernity that can be envisaged, received, reacted to, and developed in different ways and in different settings.

\section{THE PERCEPTUAL APPROACH: ANALYSIS AND DISCUSSION OF EMPIRICAL EVIDENCE}

Employing the perceptual approach in a preliminary empirical study of three notable office buildings identified based on their distinctive visual qualities where the design of their masses and facades attempt to evoke a unique image. Users of the three buildings were asked to react to five visual qualities that may be seen in the building images. These were: advanced outlook, modern technology, traditional local image and detailing, identity (uniqueness and distinction), and Islamic culture and values. Notably, over $85 \%$ of the users were either young Qataris or Arab expatriates, while others were Asians or South East Asians. ${ }^{13}$

The first building is the Qatar Islamic Cultural Centre or Al-Fanar, located in the heart of the city of Doha within walking distance from the waterfront and facing Souq Waqif, one of the oldest market places in the city. The spiraling stairway leading up to the $80 \mathrm{~m}$. high minaret is a distinguishing feature of the complex and lends it a unique singularity. Such an iconic image makes a visual reference to the minaret of the Grand Mosque of Samarra, Iraq; the 'Malwya', which makes five circuits in its rise to fifty meters. A key operating principle in the design concept is an attempt at the reinterpretation of traditional regional elements such as the 'mashrabiya' or wooden lattice windows, stained glass windows and decorative perforated screens that tend also to create an impressive composition. Metaphorically, Al-Fanar, the official name of the building, is given to signify lighthouses used in guiding navigators so that it can be comprehended as a reference point in the city (Figure 14-a). A total of 108 users have responded to the survey. The qualities of advanced outlook and traditional local image and detailing each received $19 \%$ of the

\footnotetext{
${ }^{13}$ The terms representing the five visual qualities were presented to the users with definitions in both Arabic and English languages. Advanced outlook was defined as a quality that represents the progress and aspiration of the country; modern technology was defined as a quality that manifests the use of advanced technology in construction, steel, glass in buildings; and traditional local image and detailing was defined as a quality that reflects vernacular elements found either locally or regionally. On the other hand, identity was presented to users as a quality that reflects the uniqueness of the building and whether the feel proud of being part of it; and Islamic culture and values was defined as a quality that provides impressions about proper use of entrances and aspects relevant to segregation of men and women.
} 
reactions, while modern technology received $8 \%$, identity received $23 \%$, and Islamic culture and values received $32 \%$.

Barzan Tower is the second building that was included in this study. While the building was originally designed as a government office for the Ministry of Housing, it is now used as a private office building. The design represents an attempt at combining the regular steel-cased high-rise with the traditional elements. The first nine floors are covered with an exterior traditional pattern eclectically extracted from different historical regional images. Records describing the building state that the architect's challenge is to achieve a balance between the requirements of a modern office building whilst preserving traditional Qatari architectural methods (Archnet, 2003) (Figure 14-b). A total of 158 users have responded to the survey. The qualities of advanced outlook and modern technology received $7.7 \%$ of the reactions, while traditional local image and detailing received $42.3 \%$, identity received $23 \%$, and Islamic culture and values received $13.7 \%$.

The third building is that of the headquarters of the Supreme Education Council-SEC. The design idea toward image making is similar to that of Barzan Tower; an attempt to establish a visual milieu that strives to achieve a balance between contemporary office environment and traditional imaging (Figure 14-c). A total of 116 users have responded to the survey. The quality of advanced outlook has not received any of the reactions, while modern technology received $13.8 \%$, traditional local image and detailing received $10.3 \%$, identity received $3.4 \%$, and Islamic culture and values received $62.5 \%$.

Across the reactions of the users of the three buildings, as shown in Table (1), it is evident that the qualities of advanced outlook and modern technology received the lowest responses. This can be attributed to the fact the traditional elements were perceived as more impressive visual qualities despite the presence of the glass curtain walls as in the case of Barzan Tower and the Supreme Education Council-SEC headquarters. Strikingly, the quality of advanced outlook has not received any of the users reactions in the case of SEC headquarters. This can be attributed to the heavy traditional imaging in the building entrance, façade, and the overall composition. However, a considerable number of reactions went to the quality of Islamic culture and values $(62.1 \%)$, with a few reactions to the qualities of traditional local image and detailing $(10.3 \%)$, and identity (3.4\%).
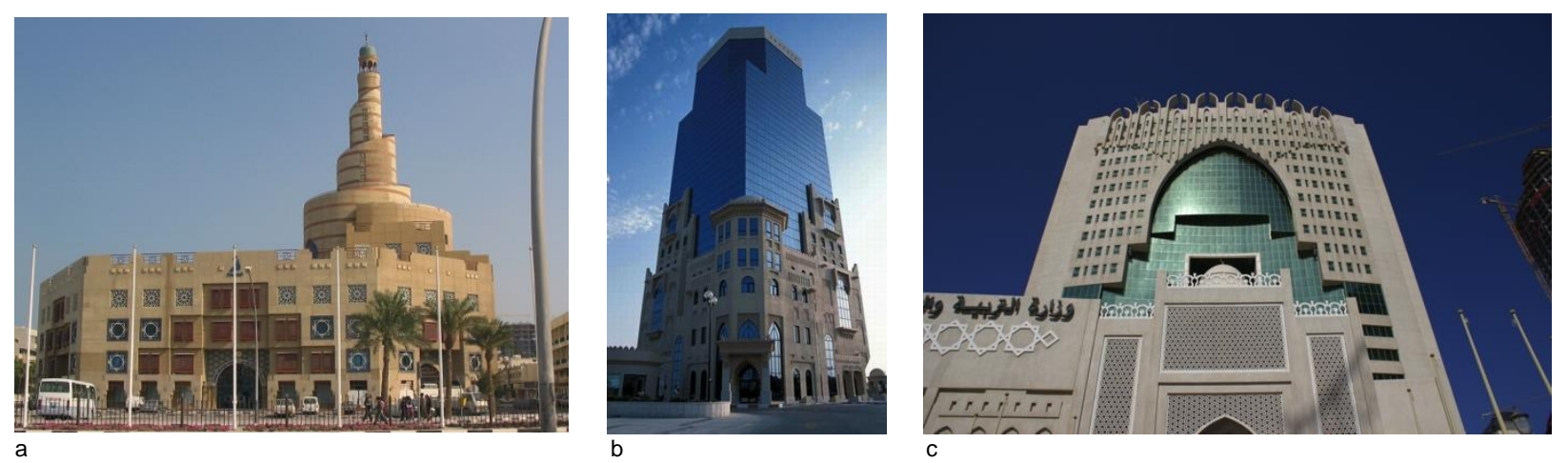

Figure 14: Office buildings identified for conducting an empirical investigation (Source: Author).

a Al-Fanar: Qatar Islamic Cultural Center by GHD Global.

b. Barzan Tower by the Qatari architect, Ibrahim M. Jaidah.

c. Supreme Education Council-SEC, by Ashghal: Public Works Authority.

Apparently, there is homogeneity across the reactions to three qualities of Al-Fanar building. The qualities of identity and Islamic culture and values received $23 \%$ and $32 \%$ respectively. This can be attributed to the dominant presence of the spiral minaret, which became a landmark for the southern area of the waterfront, while having an impact on the overall city image. Additionally, the fact that it is a 'minaret' makes the building an allegorical representation of the Islamic faith. On 
the other hand, in the case of Barzan Tower a considerable number of the reactions went to the quality of traditional local image and detailing (42.3\%). This can be attributed to the fact that the eclectic style adopted in the design of the lower part of the building offered users an opportunity to grasp the detailing of local elements and fine details. Additionally, one could interpret that the qualities of identity and Islamic culture and values received a fewer reactions $23 \%$ and $13.7 \%$ respectively due to the presence of the glass curtain walls in the upper part of the building mass, an aspect that does not distinguish the building from other surrounding buildings, when seen from a distance.

Table 1. Users' reactions to the image qualities of the three buildings examined.

\begin{tabular}{|l|l|l|l|}
\hline Image Qualities & $\begin{array}{l}\text { Al-Fanar } \\
\text { Building } \\
(108 \\
\text { responses) }\end{array}$ & $\begin{array}{l}\text { Barzan } \\
\text { Tower (158 } \\
\text { responses) }\end{array}$ & $\begin{array}{l}\text { Supreme } \\
\text { Education } \\
\text { Council HQ } \\
(116 \\
\text { responses) }\end{array}$ \\
\hline Advanced Outlook & $19 \%$ & $7.7 \%$ & 00 \\
\hline Modern Technology & $8 \%$ & $7.7 \%$ & 13.8 \\
\hline Traditional Local Image and Detailing & $19 \%$ & $42.3 \%$ & 10.3 \\
\hline Identity (uniqueness and distinction) & $23 \%$ & $23 \%$ & $3.4 \%$ \\
\hline Islamic Culture and Values & $32 \%$ & $13.7 \%$ & $62.5 \%$ \\
\hline
\end{tabular}

The previous results indicate that the three examined buildings encompass certain physical features that evoked users' reactions. Examining the five qualities in the three buildings show that they are reacted to differently by different users, mainly due to the nature of these qualities and the physical and cultural contexts within which they exist. Supporting this preceding discussion, in the context of exploring image making in the city of Doha, reference is made to an interview with a number of executives and CEOs of architectural design firms and development companies (Nair, 2010; Salama, 2010). Selected statements extracted from the interviews are outlined in Table (2).

The statements reflect a sustained commitment towards image making. They convey that it is seen as an important and explicit concern for those interviewed. They also manifest a persistent interest in image making through various forms. Yet, blending the traditional with the modern appears to be a dominant quality as expressed by the interviewees and can be found in the three buildings examined. It is evident that the status of the city of Doha is perceived in terms of both having steel and glass towers and at the same time relating to the traditional context and the images of local and regional culture, an aspect of image making that can be found in the three buildings. By and large, the statements correspond to the identified types of efforts discussed earlier and match the qualities of the buildings examined.

\section{CONCLUSION}

Contextualizing Doha within the regional cultural politics and the mapping of the global condition on the profile of the city as reflected in the production of images and places offered a critical understanding demonstrating the impact of potential and actual regional forces on the image making interests and practices. The paper established a framework for exploring image making practices in the city of Doha by identifying three approaches: the contextual, the critical, and the perceptual. On the one hand, within the contextual and critical approaches, interests and types of efforts toward image making were discussed underlying three main directions. These were: utilizing symbolism in contemporary imaging, manifesting tradition-modernity in search for image identity, and addressing the global condition towards image making. On the other hand, the perceptual approach established empirical evidence by examining users' reactions to the visual 
qualities of three notable office buildings that their design attempts to evoke a unique image. This was supported by statements made by CEOs of architectural firms and development companies, which reflected a vow towards image making in the architecture of Doha. While the analysis provides a comprehensive review of image making efforts and reactions to them, it narrates a number of crucial issues that not only characterize image making practices but also the overall intellectual environment in the city of Doha. Despite the good intentions of these practices in translating client aspirations, two points of critique can be debated. The first is the practice of borrowing 'cutting and pasting,' and the second is the absence of critical consciousness.

Table 2. Interview statements of CEOs and development directors on image making in the city of Doha.

\begin{tabular}{|c|c|}
\hline Interviewees & Statements \\
\hline $\begin{array}{l}\text { CEO of a Development } \\
\text { Company }\end{array}$ & $\begin{array}{l}\text {-We want our city to be recognized through our architecture. When someone visits } \\
\text { our city, or even sees a picture of one of our buildings in a postcard, we want them } \\
\text { to say, 'Oh yes. That is Qatar" I.M. }\end{array}$ \\
\hline $\begin{array}{l}\text { CEO of a Development } \\
\text { Company }\end{array}$ & $\begin{array}{l}\text {-The pattern of development and growth in recent decades has tended towards } \\
\text { isolated (single) land uses with a modernistic urban sprawl and heavy reliance on } \\
\text { car transport. Most aesthetic values in architecture were drawn from Western } \\
\text { influences and are marked by the anonymity of modern architecture, with very few } \\
\text { drawing inspiration from Qatari heritage." I.M. }\end{array}$ \\
\hline $\begin{array}{l}\text { CEO of Research and } \\
\text { Consulting Private } \\
\text { Institute }\end{array}$ & $\begin{array}{l}\text { - "Impacts can be mitigated by encouraging designs to align with cultural identity and } \\
\text { traditions, designing for a seamless integration into the existing cultural fabric and } \\
\text { planning for the use of local materials and workforce." Y.H. }\end{array}$ \\
\hline $\begin{array}{l}\text { CEO of Research and } \\
\text { Consulting Private } \\
\text { Institute }\end{array}$ & $\begin{array}{l}\text { - While it is important for the status of Qatar to create steel and glass towers to } \\
\text { symbolize its vibrant, modern Central Business District, elsewhere there is the need } \\
\text { to merge local characteristics of the natural environment, culture, and lifestyle to } \\
\text { create an architectural style that is uniquely our own." Y.H. }\end{array}$ \\
\hline $\begin{array}{l}\text { Director of Architecture } \\
\text { Design at Large Scale } \\
\text { Consulting Firm }\end{array}$ & $\begin{array}{l}\text { - Architectural 'style' will always be debated, however one cannot escape the } \\
\text { collective responsibility to ensure that at the very least, buildings demonstrate a } \\
\text { commitment to quality," M.H. }\end{array}$ \\
\hline $\begin{array}{l}\text { Director of Architectural } \\
\text { Design at a Large Scale } \\
\text { Consulting Firm }\end{array}$ & $\begin{array}{l}\text {-Architecture demonstrates an investment in quality and a respect for the } \\
\text { environment and its citizens. It states that you are serious when it comes to culture } \\
\text { and civic pride. My own view is that if Qatar can strike a balance between the } \\
\text { occasional landmark or iconic building, with considered urban development that } \\
\text { embodies quality in design and sensitivity to the needs of its citizens on a day-to-day } \\
\text { level, it will achieve something where many cities have failed." M.H. }\end{array}$ \\
\hline $\begin{array}{l}\text { Principal of a Medium } \\
\text { Scale Design Firm }\end{array}$ & $\begin{array}{l}\text {-We're exploring how architecture can work to bridge the gap between twenty-first } \\
\text { century design and lessons from the past. We do not want to mimic the past, but to } \\
\text { reinterpret it" S.G. }\end{array}$ \\
\hline
\end{tabular}


The practice of literal borrowing or 'cutting and pasting' involves cutting ideas from their original cultural context, whether regional or European, and pasting them in the context of the city of Doha. Such a practice is based on the belief that the new context has similar cultural circumstances and would capitulate similar results upon transfer of ideas. In this respect, one would second what Charles Correa called for "in order to build architecture, we must not copy a past, nor must we copy other people's present." (Correa, 2004:12). The practice of "cutting and pasting' does not involve enough thinking, but entails an extra effort in imaging, including selecting, cloning, and recycling of images. While the city is growing rapidly, urban governance adopted by local authorities still relies on a 'case by case decision making' which is manifested in the treatment of the urban environment in terms of individual buildings or gated and enclave developments leading to series of images reflecting different inclinations either to reflect the real or imagined past or react to the global condition. In essence, the fact that urban design has not reached a mature level in current practices is leading to urban fragmentation and social segregation rather than adopting place-making strategies.

Using elements of or borrowing from other cultures is a global phenomenon. According to Asfour (2007), some critics believe that borrowing leads to a misreading of the original, which means disintegration and deterioration in the quality of the idea. However, other critics argue that the borrowed idea should not be seen as a permanent shadow of the original, but should be regarded as a representation of a historic transfer from one setting to another (Said, 1983). This interpretation is based on the premise that a borrowed idea upon its transfer does interact with its new context and generates new elucidations. The notion of 'worldliness' introduced by Said (1983) recognizes that the local world surrounding the borrowed idea is distinct from one setting to another, and which exerts different demands and constraints on the borrowed idea in every new setting. Such a notion can be conceived as liberating the borrowed idea from its origins.

While architecture in the city of Doha is produced in a manner that is in line with client aspirations through imaging, architectural debate is suffering from internal crisis that can be exemplified by the absence of critical consciousness which may contribute to the screening of ideas. In the city of Doha borrowed ideas are not, in many cases, screened or filtered as a result of the dearth of critical consciousness. This is evident in several examples discussed underlying the three approaches. The images of the Doha Diplomatic Club (Figure 8-a), Al-Fanar Qatar Islamic Cultural Centre (Figure 14-a), Barzan Tower (Figure 14-b), Supreme Education Council (Figure 14-c) all represent scholarly copying or cloning of traditional elements. The same is palpable in the image of Qatar University (Figure 4), but involves minor abstraction or editing of the elements used. In a different manner, the act of borrowing is also apparent in the Engineering College of Texas A \& M University at the Education City by Ricardo Legoretta (Figure 10-a). The building image transmits a message related to the application of regional Mexican architecture to a wider global context. Notably, elements of Mexican architecture are an integral component of the image, including bright colors, plays of light and shadow, as well as solid volumes.

Critical consciousness represents feeling the urge to learn and criticize, and select and rationalize. Coupled with this consciousness is the appreciation that there is always an opportunity for changing or modifying the idea to sustain itself in the new setting. While there are varying degrees of success in some image making practices in Doha, many others do not involve critical consciousness; only image cloning. In essence, they are not the product of a screening apparatus generated by critical theories. Image making practices in Doha continue to subdue the profession to client aspirations through oversimplified imaging while ignoring the professional discourse that scrutinizes the quality of those images and the meanings they convey. Contemporary architecture of Doha at the beginning of the twenty-first century needs to be seen within a frame of reference that goes beyond image making to include response to environmental, socio-cultural, and socioeconomic realities. This requires a more thorough study and development of its capacity for symbolic representation in its fullest sense, if, indeed, it is to 
sustain itself as a form of human expression. With this understanding, many of the examples presented, while undoubtedly succeed in utilizing symbolism or in responding to global flows of the present era, raise many questions relevant to its socio-cultural and environmental impacts on all segments of society rather than only the elite.

\section{REFERENCES}

Altman, I. and Low, S. (1992). Place Attachment, Plenum Press, NY: New York.

Appadurai, A. (1990) Disjuncture and Difference in the Global Cultural Economy, Public Culture, 2 (2) 1-24.

Appadurai, A. (1996) Modernity at Large: Cultural Dimensions of Globalization, University of Minnesota Press, MN: Minneapolis.

ArchNet (2010) Brazan Tower: Doha, Qatar, ArchNet, Cambridge, MIT: Online. Available: [http://archnet.org/sites/5126] (Re-accessed: 6 March, 2014).

Asfour, K. (2007) Polemics in Arab Architecture, Archnet-IJAR: International Journal of Architectural Research 1 (1) 53-69.

Benjamin, W. (1968) The Work of Art in the Era of Mechanical Reproduction, Illuminations, ed. H. Arendt, Harcourt Brace \& World, IL: Chicago; 241.

Broadbent, G. (1977) Design in Architecture: Architecture and the Human Sciences, John Wiley and Sons, NY: New York.

Carmona, M.; Tiesdell, S.; Heath, T.; Tanner, OC. (2003) Public spaces - Urban Places: The Dimensions of Urban Design, Architecture Press, Oxford.

Castells, M. (1996) The Rise of the Network Society, The Information Age: Economy, Society and Culture, Blackwell, Oxford.

Castells, M. (2004) The Relationship between Globalization and Cultural Identity in the Early $21^{\text {st }}$ Century, Forum, Barcelona.

Correa, C. (1983) Quest for Identity, Architecture and Identity, ed. in R. Powell, Concept Media/The Aga Khan Award for Architecture, Singapore; 10-13.

Correa, C. (2004) Architecture for Change --Transcribed Lecture, Architecture Re-introduced: New Projects in Societies in Change, ed. J. Abed, The Aga Khan Award for Architecture; Geneva; 11-21.

Cullen, G. (1961) The Concise Townscape, Architectural Press, Oxford.

Davis, W. (1986) The Origins of Image Making, Current Anthropology, 27 (3) 193-215.

Eben Saleh, M. (1998) The Use of Historic Symbols in Contemporary Planning and Design, Cities, 15 (1) $41-47$.

Frampton, K. (1985) Towards a Critical Regionalism: Six Points for an Architecture of Resistance, The AntiAesthetic, ed. H. Foster, Bay Press, Washington; 16-30.

Grabar, O. (1980) Symbols and Signs in Islamic Architecture, Architecture as Symbol and Self-Identity, ed. J. G. Katz, Aga Khan Award for Architecture, PA: Philadelphia; 1-11.

Hall, S. (1990) Cultural Identity and Diaspora', Identity: Community, Culture, Difference, ed. J. Rutherford, Lawrence \& Wishart, London; 223-237.

Harvey, D. (1989) The Condition of Postmodernity, Blackwell, Oxford.

Hull, B.R.; Lam, M.; Vigo, G. (1994) Place Identity: Symbols of Self in the Urban Fabric, Landscape and Urban Planning, 28, 109-120.

Hasanin, A. (2007) Urban Legibility and Shaping the Image of Doha: Visual Analysis of the Environmental Graphics of the 15th Asian Games, Archnet-IJAR: International Journal of Architectural Research, 1 (3) 37-53.

Huntington, S. (1998) The Clash of Civilizations and the Remaking of World Order Simon and Schuster, NY: New York.

Hendrix, J. (2010) Architecture as the Psyche of a Culture, School of Architecture, Art, and Historic Preservation, Faculty Papers \# 8 (Bristol, Roger Williams University. Online. Available: [http://docs.rwu.edu/saahp fp/8] (2 May 2010).

Huxtable, A. L. (1981) The Troubled State of Modern Architecture, Architectural Record, 169 (March) $72-$ 79.

Jencks, C. (2005) The Iconic Building: The Power of Enigma, Frances Lincoln, London. 
Larice, M. and Macdonald, E. eds. (2007) The Urban Design Reader, Routledge-Taylor and Francis Group, London and New York.

Lefebvre, H. The Production of Space, Blackwell, Oxford.

Lynch, K. (1960) The Image of the City, MIT Press, MA: Cambridge.

Mahgoub, Y. (2007) Architecture and the Expression of Cultural Identity in Kuwait, The Journal of Architecture, 12 (2) 165-182.

Mazzoleni, D. (2005) Introduction, Shores of the Mediterranean: Architecture as Language of Peace, eds. D. Mazzoleni, G. Anzani, A. M. Salama, M. Sepe, M. M. Simone, Intra Moenia, Napoli; 3-9.

Nair, S. (2010) Capital Dreams Qatar's Quest for Architectural Distinction, Qatar Today, (March) 40-45.

Nasar, J. L. (1988) Environmental Aesthetics: Theory, Research, and Application, Cambridge University Press, MA: Cambridge.

OLE, B. (2005) Branding the Contemporary City - Urban Branding as Regional Growth Agenda?, Plenary Paper for Regional Studies Association Conference Regional Growth Agendas Aalborg.

Özkan, S. (1989) Regionalism within Modernism, Space for Freedom, ed. I. Serageldin, Butterworth Architecture, London; 8-16.

Pallasmaa, J. (2005) The Eyes of the Skin: Architecture and the Senses, John Wiley and Sons, Chichester.

Said, E. (1983) The World, the Text and the Critic, Harvard University Press, MA: Cambridge.

Sadria, M. (ed.) (2012) Homogenisation of Representations, Aga Khan Award for Architecture, Geneva.

Salama, A. M. (2005) Architectural Identity in the Middle East: Hidden Assumptions and Philosophical Perspectives, Shores of the Mediterranean: Architecture as Language of Peace, eds. D. Mazzoleni, G. Anzani, A. M. Salama, M. Sepe, M. M. Simone, Intra Moenia, Napoli; 77-85.

Salama, A. M. (2008) Doha: Between Making an Instant City and Skirmishing Globalization, Middle East Institute-Viewpoints, American University, DC: Washington; 40-44.

Salama, A. M. (2010) Architectural Aspirations of an Emerging Metropolis, Qatar Today, (March) 46-48.

Salama, A. M. (2011) Identity Flows: The Arabian Peninsula, Emerging Metropolises, Atlas Architectures of the 21st Century - Africa and Middle East, ed. L. Fernández-Galiano, Madrid, BBVA Foundation; 175-221.

Salama, A. M., and Wiedmann, F. (2013) Demystifying Doha: On Architecture and Urbanism in an Emerging City, Ashgate Publishing Ltd, Farnaham/London.

Salama, Hussam H. (2013). Dubai in a World of Flows, Archnet-IJAR: International Journal of Architectural Research, 7 (2) 136-145.

Strauss, A. L. (1969) Mirrors and Masks: The Search for Identity, The Sociology Press, CA: San Francisco.

Strauss, A. L. (1991) Creating Sociological Awareness: Collective Images and Symbolic Representations, Transaction Publishers, NJ: New Brunswick.

Rapoport, A. (1970) The Study of Spatial Quality, Journal of Aesthetic Education - Special Issue: The Environment and the Aesthetic Quality of Life, 4 (4) 81-95.

Saliya, Y. (1986) Notes on the Architectural Identity in the Cultural Context, MIMAR 19: Architecture in Development, 32-33.

Sanoff, H. (1974) Measuring Attributes of the Visual Environment, Designing for Human Behavior: Architecture and the Behavioral Sciences, eds. J. T. Lang, C. Burnette, W. Moleski, D. Vachon, Dowden, Hutchinson and Ross, Stroudsburg; 244-260.

Sanoff, H. (1991) Visual Research Methods in Design, Van Nostrand Reinhold, NY: New York.

Sennett, R. (1970) The Uses of Disorder: Personal Identity and City Life. Vintage, NY: New York.

Sennett, R. (1992) The Consciences of the Eye: The Design and Social life of Cities. Faber and Faber, London.

Stamp, A. E. (2000) Psychology and the Aesthetics of the Built Environment, Springer, NY: New York.

Stillerman, J. (2006) The Politics of Space and Culture, Qualitative Sociology, (29) 507-530.

Synnott, M. (2010) Towards an Ontological Understanding of City Branding, 14 th IRSPM: Challenges for Public Management, Berne.

Taylor, P. J. (2003) World City Network: A Global Urban Analysis, Routledge, London.

Thierstein, A. and Schein, E. (2008) Emerging Cities on the Arabian Peninsula: Urban Space in the Knowledge Economy Context, Archnet-IJAR: International Journal of Architectural Research, 2 (2) 178-195.

Tzonis, A., Lefaivre, L. (2003) Critical Regionalism: Architecture and Identity in a Globalized World, Prestel, NY: New York. 


\section{ArchNet}

Vesely, D. (2004) Architecture in the Age of Divided Representation: The Question of Creativity in the Shadow of Production, MIT Press, MA: Cambridge.

Zube, E. (1984) Environmental Evaluation: Perception and Public Policy, Cambridge University Press, MA: Cambridge.

\section{AUTHOR}

\section{Ashraf M.Salama, PhD}

Professor of Architecture

Department of Architecture,

Faculty of Engineering, University of Strathclyde,

Glasgow, Scotland, UK

ashraf.salama@strath.ac.uk 